\title{
Disabling an integral CTL epitope allows suppression of autoimmune diabetes by intranasal proinsulin peptide

\author{
Nathan R. Martinez, ${ }^{1}$ Petra Augstein, ${ }^{1}$ Antonis K. Moustakas, ${ }^{2}$ George K. Papadopoulos, ${ }^{2}$ \\ Silvia Gregori, ${ }^{3}$ Luciano Adorini, ${ }^{3}$ David C. Jackson, ${ }^{4}$ and Leonard C. Harrison ${ }^{1}$
}

\author{
${ }^{1}$ Autoimmunity and Transplantation Division, The Walter and Eliza Hall Institute of Medical Research, Parkville, Australia \\ ${ }^{2}$ Laboratory of Biochemistry and Biophysics, Faculty of Agricultural Technology, \\ Technological Educational Institute of Epirus, Arta, Greece \\ ${ }^{3}$ Roche Milano Ricerche, Milan, Italy \\ ${ }^{4}$ Department of Microbiology and Immunology, University of Melbourne, Parkville, Australia
}

\begin{abstract}
Insulin is a major target of the autoimmune response associated with destruction of pancreatic $\beta$ cells in type 1 diabetes. A peptide that spans the junction of the insulin B chain and the connecting (C) peptide in proinsulin has been reported to stimulate $T$ cells from humans at risk for type 1 diabetes and autoimmune diabetes-prone NOD mice. Here we show that proinsulin B24-C36 peptide binds to $\mathrm{I}-\mathrm{A}^{\mathrm{g}}$, the MHC class II molecule of the NOD mouse, and, after intranasal administration, induces regulatory $\mathrm{CD}^{+} \mathrm{T}$ cells that, in the absence of $\mathrm{CD}^{+} \mathrm{T}$ cells, block the adoptive transfer of diabetes. Curiously, however, intranasal B24-C36 did not inhibit development of spontaneous diabetes in treated mice. We then determined that $\mathrm{B} 24-\mathrm{C} 36$, and its core sequence $\mathrm{B} 25-\mathrm{C} 34$, bind to $\mathrm{K}^{\mathrm{d}}$, the NOD mouse MHC class I molecule, and elicit $\mathrm{CD}^{+} \mathrm{CTLs}$. When the $\mathrm{CD}^{+} \mathrm{T}$ lymphocyte epitope was truncated at the $\mathrm{C} 34$ valine anchor residue for binding to $\mathrm{K}^{\mathrm{d}}$, the residual $\mathrm{CD}^{+} \mathrm{T}$ cell epitope, B24-C32/33, significantly inhibited diabetes development after a single intranasal dose. This study identifies a novel CTL epitope in proinsulin and demonstrates that the therapeutic potential of a "tolerogenic" autoantigen peptide can be compromised by the presence of an integral CTL epitope.
\end{abstract}

J. Clin. Invest. 111:1365-1371 (2003). doi:10.1172/JCI200317166.

\section{Introduction}

In type 1 diabetes (T1D), $\mathrm{T}$ cells target and destroy insulin-producing $\beta$ cells in the islets of the pancreas. Several lines of evidence indicate that proinsulin plays a key role as an autoantigen in driving this process. For example, susceptibility of humans to T1D maps to a variable number of tandem repeats $5^{\prime}$ of the insulin gene, the length of which correlates with thymic expression of proinsulin mRNA and inversely with disease risk $(1,2)$. In the NOD mouse, a model of spontaneous autoimmune diabetes, transgenic expression of proinsulin in APCs prevents mononuclear cell infiltration of the islets (insulitis) and diabetes (3). A peptide in human proinsulin that spans the cleavage site between the $B$ chain of insulin and the connecting $(C)$ peptide in proinsulin, B24-C36, was shown to stimulate peripheral blood $\mathrm{T}$ cells from humans at risk for T1D (4). Recently, a peptide spanning the B-C chain

Received for publication October 16, 2002, and accepted in revised form February 11, 2003.

Address correspondence to: Leonard C. Harrison, The Walter and Eliza Hall Institute of Medical Research, IG Royal Parade, Parkville 3050, Australia. Phone: 61-3-9345-2460;

Fax: 61-3-9347-0852; E-mail: harrison@wehi.edu.au.

Conflict of interest: The authors have declared that no conflict of interest exists.

Nonstandard abbreviations used: type 1 diabetes (T1D); hen-egg lysozyme (HEL); Listeria monocytogenes listeriolysin O (LLO); $\mathrm{T}$ cell receptor (TCR). junction in mouse proinsulin II was shown to contain a naturally processed epitope for autoreactive T cells in young NOD mice (5).

Peptide autoepitopes are candidate therapeutic agents for preventing autoimmune disease (6). Mucosal administration of a peptide antigen can suppress subsequent systemic immune priming by the antigen (mucosal tolerance) and has been used to inhibit a range of experimental autoimmune diseases (6-8). We therefore administered proinsulin B24-C36 peptide intranasally to NOD mice in the expectation that it would inhibit the development of diabetes. However, although intranasal B24-C36 elicited antidiabetogenic regulatory $\mathrm{T}$ cells, it did not protect mice from diabetes. In exploring the reason for this, we determined that proinsulin B24-C36 is a novel "combitope" comprising not only an MHC class II-restricted T cell epitope that elicits regulatory $\mathrm{CD} 4^{+} \mathrm{T}$ cells but also an overlapping MHC class I-restricted epitope capable of eliciting CTLs that can nullify the therapeutic effect.

\section{Methods}

Mice. NOD mice (Lt/Jax) were bred under specific pathogen-free conditions at The Walter and Eliza Hall Institute of Medical Research. Diabetes was diagnosed if two sequential measurements of retro-orbital venous blood glucose exceeded $11 \mathrm{mM}$.

Protein and peptides. Mouse proinsulin II peptides B24-C36 (FFYTPMSRREVED), B24-C32, B24-C33, 
B25-C33, B26-C34, and B25-C34, hen-egg lysozyme (HEL) 10-23, and Listeria monocytogenes listeriolysin O (LLO) 91-99 (GYKDGNEYI) were synthesized and purified to greater than $95 \%$ homogeneity, determined by HPLC-MS, by Mimotopes (Melbourne, Australia). OVA (Sigma-Aldrich, St. Louis, Missouri, USA) and peptides were resuspended in PBS.

Intranasal administration of peptides. In a series of preliminary experiments, unanesthetized female NOD mice (12 per group) were given either carrier PBS or 0.4, 4,40 , or $80 \mu \mathrm{g}$ of mouse proinsulin B24-C36 in $10 \mu \mathrm{l}$ PBS intranasally on three alternating days from 8 weeks of age, and their incidence of diabetes was monitored out to 26 weeks of age. The 0.4 and $4 \mu \mathrm{g}$ of mouse proinsulin had no effect, whereas both the 40 and $80 \mu \mathrm{g}$ of mouse proinsulin had a small $(11 \%-24 \%)$ effect to decrease diabetes incidence. Subsequently, 40 $\mu \mathrm{g}$ of test or control peptide was given on three alternating days. In diabetes incidence studies, blood glucose was measured every 4 weeks from 100 days of age. Adoptive transfer of diabetes. Male 6- to 9-week-old NOD mice (8 or 12 per group) were irradiated (8 Gy) from a cobalt source and 3-6 hours later received $10^{7}$ pooled diabetogenic splenocytes from recently NOD female mice, together with $10^{7}$ splenocytes or cells fractionated from this number from either proinsulin peptideor OVA-treated mice, in $200 \mu \mathrm{l}$ via the tail vein. The onset of diabetes was monitored every 2 weeks by measuring blood glucose beginning 2 weeks after transfer. Fractionation of spleen cells. Splenic $\mathrm{CD}^{+}$and $\mathrm{CD}^{+}$ cells were either selected or depleted by magnetic separation with monoclonal antibodies bound to MACS microbeads (Miltenyi Biotec GmbH, Bergisch Gladbach, Germany). The yield of $\mathrm{CD}^{+}$and $\mathrm{CD}^{+}$cells was $70 \%-80 \%$ and $20 \%-30 \%$, respectively, and their depletion or purity by flow cytometry more than $95 \%$ and more than $85 \%$, respectively.

$I-A^{g 7}$ binding assay. Binding of peptides to purified, soluble $\mathrm{I}-\mathrm{A}^{\mathrm{g} 7}$ was measured in an ELISA as previously described (9). Competition dose-response binding curves were generated, and peptide binding affinity for $\mathrm{I}-\mathrm{A}^{\mathrm{g}}$ was expressed as an $\mathrm{IC}_{50}$, the molar concentration of peptide that inhibited by $50 \%$ binding of the indicator peptide, N-terminal biotinylated HEL 10-23.

Prediction of peptides that bind to MHC class I. Peptides within mouse proinsulin II B24-C36 that could potentially bind to the NOD mouse MHC class I molecules, $\mathrm{K}^{\mathrm{d}}$ and $\mathrm{D}^{\mathrm{b}}$, were identified in the Web-based databases SYFPEITHI (10) and BIMAS (11).

Modeling of peptide binding to MHC molecules. When homology modeling was performed, no crystal structures of $\mathrm{K}^{\mathrm{d}}$ or I-Ag7 were available. The two crystal structures of $\mathrm{I}-\mathrm{Ag}^{\mathrm{g}}$ published subsequently $(12,13)$ agree in nearly all respects with the modeled structure used here (14). Modeling of $\mathrm{I}-\mathrm{A}^{\mathrm{g} 7}$ was based on the coordinates of the I-A $\mathrm{A}^{\mathrm{k}}$ /HEL 50-62 peptide complex (15) and was performed with the program Discover II of Accelrys (San Diego, California, USA). Modeling of $\mathrm{K}^{\mathrm{d}}$ was based on the coordinates of HLA-A2 hepatitis B nucleocapsid 18-27 peptide

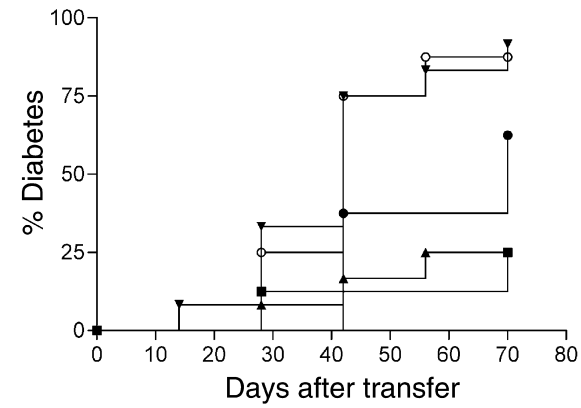

\section{Figure 1}

Intranasal proinsulin B24-C36 induces CD4 ${ }^{+} \mathrm{T}$ cells that block adoptive transfer of diabetes. Female 8 -week-old NOD mice $(n=4$ per group) were given $40 \mu \mathrm{g}$ of proinsulin B24-C36 peptide or OVA protein in $10 \mu \mathrm{lPBS}$, intranasally on three alternating days. Two weeks after the last treatment, the mice were killed and $10^{7}$ pooled splenocytes from mice treated with proinsulin B24-C36 (filled circles) or OVA (open circles), or $10^{7}$ pooled splenocytes from mice treated with proinsulin B24-C36 either selected for $\mathrm{CD}^{+}$cells (filled triangles) or depleted of either $\mathrm{CD}^{+}$(filled inverted triangles) or $\mathrm{CD}^{+}$(filled squares) cells, were cotransferred with $10^{7}$ pooled splenocytes from recently NOD female mice into irradiated young NOD male recipients ( $n=8$ or 12 per group). The development of diabetes in recipients after transfer was monitored by measuring blood glucose every 2 weeks. Results are representative of five similar experiments.

complex (16) (Protein Data Bank access code: 1hhh.pdb [ref. 15]). We found that HLA-A2 is a better base molecule for modeling $\mathrm{K}^{\mathrm{d}}$ than the more homologous mouse $\mathrm{K}^{\mathrm{b}}$, giving better agreement with binding and $\mathrm{T}$ cell proliferation data for variants of the insulin B15-23 CTL epitope (17). The modeling procedure for $\mathrm{K}^{\mathrm{d}}$ was identical to that for $\mathrm{I}-\mathrm{A}^{\mathrm{g} 7}$, at an ambient $\mathrm{pH}$ of 7.0. The models are shown in solid-surface representation with colors according to the surface electrostatic potential (gray, neutral; blue, positive; red, negative). The peptide residues are in van der Waals space-filling form, whereas selected MHC heavy chain residues shown are in stick representation (oxygen, red; nitrogen, blue; carbon, green; hydrogen, white). Secondary structure elements of the MHC molecule are also shown for orientation purposes: $\alpha$-helix in red, $\beta$-pleated sheet in turquoise, and random coil in gray. A transparency function has been included to allow secondary structural elements of the MHC molecule and the peptide residues buried in it to be slightly visible.

$K^{d}$-peptide binding stabilization assay. $\mathrm{K}^{\mathrm{d}}$-transfected RMA-S cells (18), $10^{4}$ cells per well, were incubated overnight at $27^{\circ} \mathrm{C}$ in RPMI-1640 medium with $100 \mu \mathrm{M}$ test peptide, heat-shocked for 2 minutes at $56^{\circ} \mathrm{C}$, washed, and incubated with anti- $\mathrm{K}^{\mathrm{d}}$ antibody (34-1-2S) for 30 minutes at $4^{\circ} \mathrm{C}$, followed by FITC-conjugated sheep anti-mouse immunoglobulin (Silenus Laboratories, Victoria, Australia). LLO 91-99, known to bind $\mathrm{K}^{\mathrm{d}}$ with high affinity (19), was used as a reference peptide. Cells were examined with a FACScan flow cytometer (Becton Dickinson Immunocytometry Systems, San Jose, California, USA) that used CellQuest software. Binding of peptide to $\mathrm{K}^{\mathrm{d}}$ is observed as a temperaturedependent stabilization of surface $\mathrm{K}^{\mathrm{d}}$ expression. 
Chromium $\left[{ }^{51} \mathrm{Cr}\right]$-release CTL assay. Effector cells were generated in female NOD mice by subcutaneous injection of $50 \mu \mathrm{g}$ peptide in CFA (Difco Laboratories, Detroit, Michigan, USA). After 14 days, splenocytes were harvested and restimulated in vitro for 6 days in HEPES Eagle's Medium (HEM) $2.5 \% \mathrm{FCS}$ at $37^{\circ} \mathrm{C}$ with peptide-coated $(10 \mu \mathrm{g} / \mathrm{ml})$ irradiated (15 Gy) splenocytes (20). Restimulated effector cells $(100 \mu \mathrm{l})$ were then seeded in duplicate with $10^{4}$ chromium [ $\left.{ }^{51} \mathrm{Cr}\right]$-labeled RMA-S-K $\mathrm{K}^{\mathrm{d}}$ target cells $(100 \mu \mathrm{l})$ prepulsed with $100 \mu \mathrm{M}$ peptide. RMA-S-K ${ }^{\mathrm{d}}$ targets were prepared by incubating $1 \times 10^{6}$ cells with 100 $\mu \mathrm{M}$ peptide and $100 \mu \mathrm{Ci}{ }^{51} \mathrm{Cr}$ in $200 \mu \mathrm{l}$ for 2 hours at $27^{\circ} \mathrm{C}$. Plates were incubated for 6 hours at $37^{\circ} \mathrm{C}$ in $5 \%$ $\mathrm{CO}_{2}$ /air. Percent specific lysis (cpm in $100 \mu \mathrm{l}$ supernatant) was determined as (experimental release - medium release $) /($ maximum release - medium release $) \times 100$.

Statistical analysis. Group differences were analyzed with Fisher exact test (two-tailed) and differences between Kaplan-Meier survival curves were analyzed by the log-rank test, with the use of GraphPad Prism version 3.0a for Macintosh (GraphPad Software Inc., San Diego, California, USA).

\section{Results}

Intranasal proinsulin $B 24-C 36$ induces $C D 4^{+}$regulatory $T$ cells but fails to suppress spontaneous diabetes. Female 8week-old NOD mice were treated with three intranasal doses of proinsulin B24-C36 peptide. Two weeks later, their unfractionated splenocytes or splenocytes from which $\mathrm{CD}^{+}$or $\mathrm{CD}^{+}$cells had been depleted or selected, were cotransferred with splenocytes from other recently diabetic NOD mice into young irradiated NOD males. Cotransfer of splenocytes from NOD mice given intranasal proinsulin peptide B24-C36 with diabetogenic splenocytes modestly decreased the incidence of diabetes in recipients $(P=0.05)$ (Figure 1$)$. Diabetes incidence was significantly reduced by cotransfer of

\footnotetext{
Figure 2

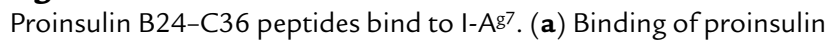
B24-C36 peptides to purified, soluble NOD mouse MHC class II, $\mathrm{I}-\mathrm{A}^{\mathrm{g}}{ }^{7}$. Competition between biotinylated HEL 10-23 peptide and unlabeled HEL 10-23 (open squares), proinsulin B24-C36 (filled circles), B23-C33 (open triangles), or B22-C31 (filled diamonds) for binding to $\mathrm{I}-\mathrm{Ag} 7$ measured by ELISA. (b) Model of B24-C36 bound to $\mathrm{I}^{\mathrm{g}} \mathrm{g}^{7}$ at $\mathrm{pH} 7.0$, viewed from the perspective of the $\mathrm{T}$ cell receptor (TCR). Anchor residues at position 1F (p1F) (B24) and p9R (C32) point into the groove of $\mathrm{I}-\mathrm{Ag}^{\mathrm{g}}$ and are only partially visible. The $\mathrm{p} 4 \mathrm{~T}$ points into the groove at pocket 4 and is partially visible, as is $p 6 \mathrm{M}$. By contrast, residues at $\mathrm{p} 2 \mathrm{~F}, \mathrm{p} 3 \mathrm{Y}, \mathrm{p} 5 \mathrm{P}, \mathrm{p} 7 \mathrm{~S}$, and $\mathrm{p} 8 \mathrm{R}$ point upward and are accessible by the TCR. Note the interaction of $\alpha 75 \mathrm{~K}$ and $\alpha 76 \mathrm{R}$ with the three acidic residues at the $\mathrm{C}$-terminus of the peptide as shown in the main figure and in the bottom right-hand corner inset. The latter is generated by rotating this segment of the main figure by 40 degrees along the $x$ axis (bottom up, top into the paper) and 20 degrees along the $y$ axis (right up, left into the paper). $\alpha 75 \mathrm{~K}$ interacts with the side chain carboxylate (and secondarily the terminal carboxylate) of p13D (C36), while $\alpha 76 \mathrm{R}$ interacts with $\mathrm{p} 10 \mathrm{E}$ (C33) and P12E (C35).
}

either purified splenic $\mathrm{CD}^{+}$cells or splenocytes depleted of $\mathrm{CD}^{+}$cells from mice given intranasal proinsulin B24-C36 ( $P=0.008$ for both compared with splenocytes depleted of $\mathrm{CD}^{+}$cells) (Figure 1). Intriguingly, however, intranasal proinsulin peptide given in a single dose, or in three doses either on alternating days from 8 weeks of age or monthly from 4 weeks of age, had only a small effect to suppress spontaneous diabetes development in female NOD mice monitored for 26 weeks or longer (data not shown). These results suggested to us that intranasal B24-C36 could have induced not only regulatory $\mathrm{CD}^{+}$but also pathogenic $\mathrm{CD}^{+} \mathrm{T}$ cells, with a net neutral effect of the whole splenocyte population on disease transfer.

Proinsulin B24-C36 comprises overlapping MHC class IIand class I-restricted epitopes. To determine whether proinsulin B24-C36 comprised epitopes for both $\mathrm{CD}^{+}$ and $\mathrm{CD}^{+} \mathrm{T}$ cells, we first analyzed B24-C36 for MHC class II- and class I-binding peptides. B24-C36 and the shorter peptide $\mathrm{B} 23-\mathrm{C} 33$ bound to $\mathrm{I}^{-\mathrm{A}^{\mathrm{g}} 7}$, the $\mathrm{MHC}$ class II molecule of NOD mice, with relatively high affinity $\left(\mathrm{IC}_{50}=3-5 \mu \mathrm{M}\right)$ compared with the reference HEL 10-23 peptide (Figure 2a). Conversely, proinsulin B22-C31 failed to bind to I-Ag7. Homology modeling (Figure $2 \mathrm{~b}$ ) revealed that the core nonamer sequence accommodated in I-Ag7 was B24-C32 (FFYTPMSRR). However, the three acidic residues beyond position (p) 9 in B24-C36, that is, p10E (C33), p12E (C35), and
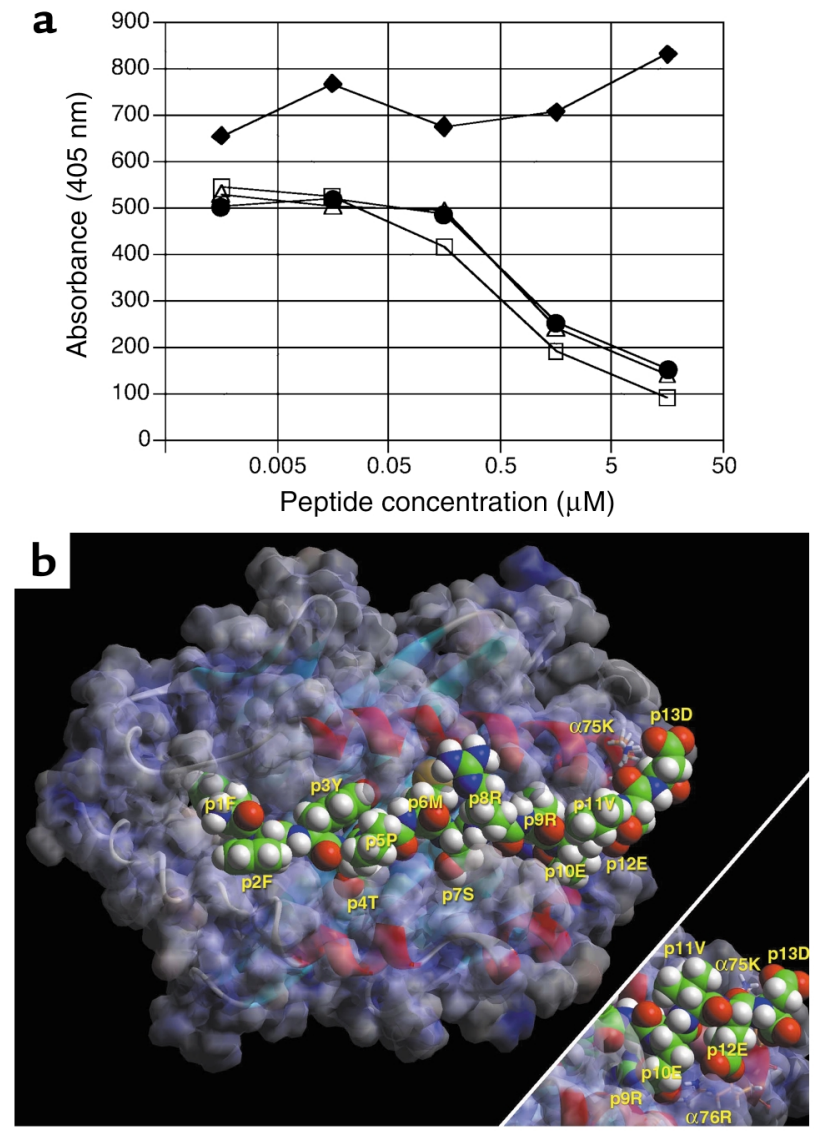

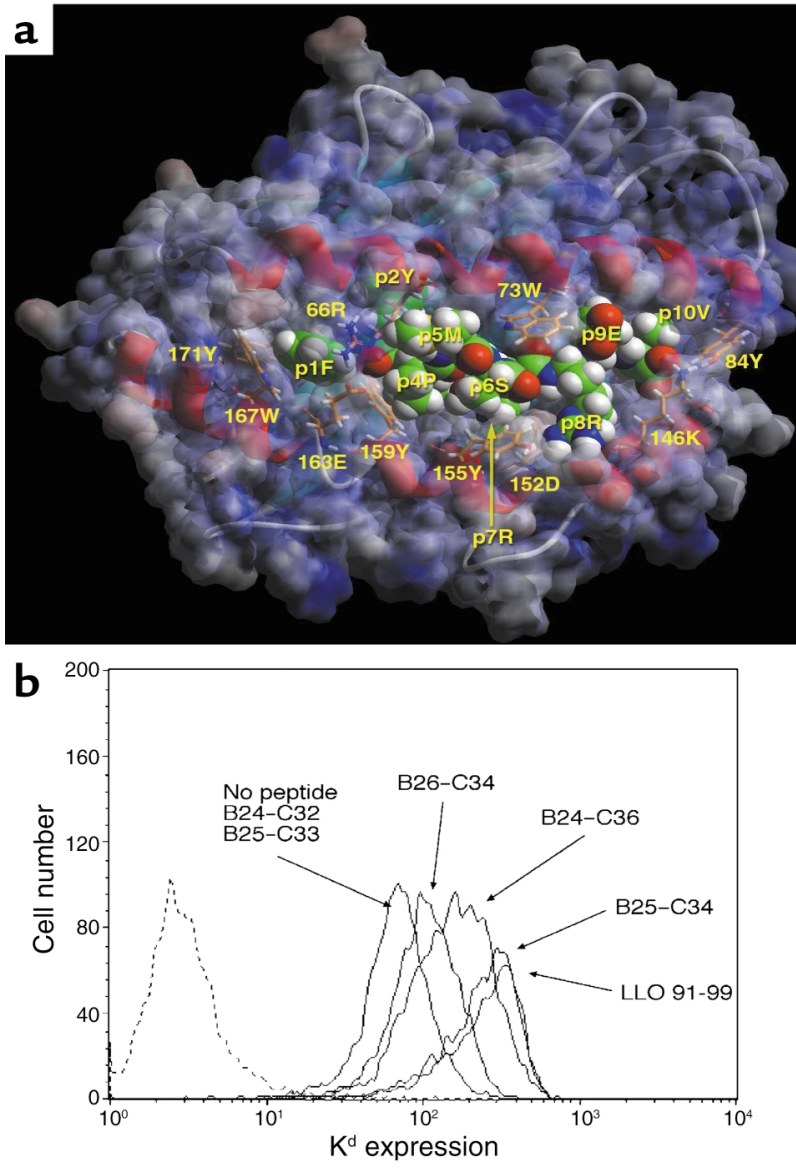

p13D (C36), have the capacity to greatly enhance binding by forming salt bridges with $\mathrm{I}^{-\mathrm{A}^{\mathrm{g}} 7} \alpha$ chain $76 \mathrm{R}$ (C33, $\mathrm{C} 35)$ and $75 \mathrm{~K}(\mathrm{C} 36)$. There is also an interaction between R (C32) and E (C33), probably accommodated because of the wider opening of the $\mathrm{p} 9$ pocket in I-Ag7 compared with other MHC class II alleles (12-14).

To identify peptides in B24-C36 that might bind to NOD MHC class I molecules $\left(\mathrm{K}^{\mathrm{d}}\right.$ and $\left.\mathrm{D}^{\mathrm{b}}\right)$, we initially scanned the Web-based peptide motif databases SYFPEITHI (10) and BIMAS (11). Three overlapping nonamers, B24-C32, B25-C33, and B26-C34, and one decamer, B25-C34, were identified as potential binders to $\mathrm{K}^{\mathrm{d}}$. Homology modeling (Figure $3 \mathrm{a}$ ) revealed that the core binding sequence was likely to be the decamer, B25-C34, with anchor residues for $\mathrm{K}^{\mathrm{d}}$ binding at $\mathrm{p} 2(\mathrm{Y})$ and $\mathrm{p} 10(\mathrm{~V})$. To confirm this prediction, we performed direct binding studies of synthetic peptides to cell surface $\mathrm{K}^{\mathrm{d}}$, using the TAP-deficient cell line RMA-S stably transfected with $\mathrm{K}^{\mathrm{d}}$. The B25-C34 decamer and, to a lesser extent, B24-C36 itself and the B26-C34 nonamer, but not B24-C32, B24-C33, or B25-C33, were observed to bind to $\mathrm{K}^{\mathrm{d}}$ (Figure $3 \mathrm{~b}$ ).

The $\mathrm{K}^{\mathrm{d}}$-binding $\mathrm{B} 26-\mathrm{C} 34$ and $\mathrm{B} 25-\mathrm{C} 34$ peptides were then tested to determine whether they could prime $\mathrm{K}^{\mathrm{d}}$-restricted CTLs. Female NOD mice were immunized by subcutaneous injection of $50 \mu \mathrm{g}$ of peptide in CFA. Spleen cells were recovered after 14 days and restimulated with peptide in culture before assay

\section{Figure 3}

Proinsulin B24-C36 peptides bind to $\mathrm{H} 2-\mathrm{K}^{\mathrm{d}}$. (a) Model of proinsulin B25-C34 bound to $\mathrm{H}-2 \mathrm{~K}^{\mathrm{d}}$ at $\mathrm{pH} 7.0$, viewed from the perspective of the TCR. Anchor residues at $\mathrm{p} 2 \mathrm{Y}$ and $\mathrm{p} 10 \mathrm{~V}$ point into the groove of $\mathrm{K}^{\mathrm{d}}$ and are only partially visible. The $\mathrm{P} 3 \mathrm{~T}$ points into the groove at pocket $\mathrm{D}$ and is not visible. The $\mathrm{p} 7 \mathrm{R}$ points into the groove at pocket $E$ and is partly visible. By contrast, residues at p1F, p4P, p5M, p6S, $\mathrm{p} 8 \mathrm{R}$, and $\mathrm{p} 9 \mathrm{E}$ point upward and are thus accessible by the TCR. Note the tight packing of $1 \mathrm{~F}$ into pocket $\mathrm{A}$ and against $167 \mathrm{~W}$, as well as the interaction of these aromatic residues with 171Y. Residue 152D is below p8R and forms a salt bridge with it (not shown), while 155Y has its aromatic plane nearly parallel to the plane of the paper. (b) Proinsulin B26-C34, B24-C36, and B25-C34 bind to H2-Kd. TAPdeficient RMA-S- $K^{d}$ cells were incubated in medium alone (no peptide) or in the presence of the indicated proinsulin peptides, or reference LLO peptide, and the level of surface $\mathrm{K}^{\mathrm{d}}$ expression was then measured by flow cytometry. Cells incubated in media alone were also stained with an isotype control antibody (dotted line).

against ${ }^{51} \mathrm{Cr}$-labeled RMA-S- $\mathrm{K}^{\mathrm{d}}$ cells prepulsed with peptide. In accordance with their ability to bind $\mathrm{K}^{\mathrm{d}}$, B25-C34 and, to a lesser extent, B26-C34 elicited CTLs capable of lysing target RMA-S cells and releasing ${ }^{51} \mathrm{Cr}$ (Figure 4). It is noteworthy that B24-C36 could prime CTLs able to recognize not only B24-C36 itself, but also B25-C34. Priming with the non- $\mathrm{K}^{\mathrm{d}}$ binding peptides, B24-C32, B24-C33, and B25-C33, failed to induce CTLs (data not shown). CTLs were consistently demonstrated after subcutaneous immunization with B24-C36 in adjuvant but could not be reliably detected after intranasal B24-C36.

Treatment with the $K^{d}$-restricted CTL epitope, proinsulin B25-C34, reduces diabetes incidence. Systemic administration of autoepitope peptides with or without incomplete Freund's adjuvant (IFA) has been reported to trigger antigen-induced cell death and delete autoantigen-specific $\mathrm{T}$ cells (21-24). To obtain evidence that B25-C34-specific CTLs may be involved in $\beta$ cell destruction, $50 \mu \mathrm{g}$ of B25-C34 in IFA was administered intraperitoneally to female NOD mice $(n=10)$ at 18 days of age, before the onset of insulitis. This treatment delayed diabetes onset and reduced the incidence of diabetes to $30 \%$ at 280 days, compared with $70 \%$ in mice similarly treated with either B24-C32 or HEL 10-23 $(P=0.03)$.

Disabling the B25-C34 CTL epitope permits diabetes prevention by intranasal peptide. To determine whether the failure of intranasal B24-C36 to prevent spontaneous diabetes, despite induction of regulatory $\mathrm{CD} 4^{+} \mathrm{T}$ cells, was due to the B25-C34 CTL epitope, B24-C36 was truncated at the $\mathrm{C}$-terminus to eliminate the $\mathrm{C} 34$ valine anchor residue for binding to $\mathrm{K}^{\mathrm{d}}$. To confirm that intranasal administration of the truncated B24-C33 peptide could induce regulatory $\mathrm{CD}^{+} \mathrm{T}$ cells, $40 \mu \mathrm{g}$ of the peptide was administered intranasally to NOD mice on three alternating days from 8 weeks of age. Two weeks later, $10^{7}$ splenocytes, $10^{6}$ purified splenic $\mathrm{CD} 4^{+}$cells, or $10^{7}$ splenocytes depleted of $\mathrm{CD} 4^{+}$cells, from treated mice, were cotransferred intravenously 


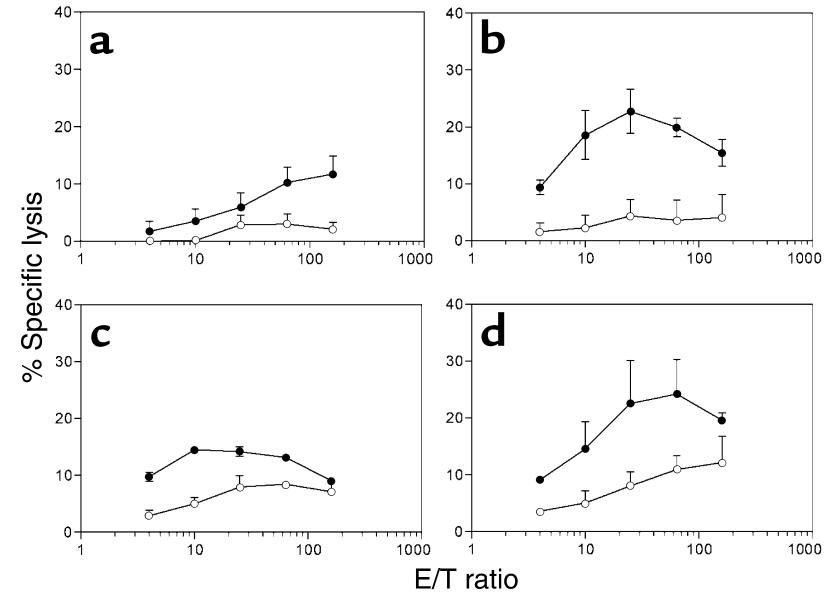

Figure 4

Proinsulin B25-C34 elicits $\mathrm{K}^{\mathrm{d}}$-restricted CTLs. Female NOD mice were primed subcutaneously with proinsulin peptide B26-C34 (a), B25-C34 (b), or B24-C36 (c and d) in CFA. Splenocytes from primed mice were then restimulated in culture with B26-C34 (a and c) or B25-C34 (b and d), and CTL activity was assayed. Restimulated spleen cells as effectors (E) were tested for their ability to induce release of radioactivity from ${ }^{51} \mathrm{Cr}$-labeled RMA-S- $K^{\mathrm{d}}$ cells as targets $(T)$ in the absence of added peptide (open circles) or after loading with specific peptide (filled circles), either B26-C34 (a and $\mathbf{c}$ ) or B25-C34 (b and d).

with $10^{7}$ splenocytes from recently NOD females into irradiated 6-week-old NOD males ( $n=12$ per group). Splenic $\mathrm{CD}^{+}$cells from mice that had received intranasal B24-C33 prevented transfer of diabetes: 6 weeks after cotransfer, only one of eight recipients of whole splenocytes and none of the eight recipients of purified splenic $\mathrm{CD}^{+}$cells from B24-C33-treated mice were diabetic, in contrast to seven of the eight recipients of splenocytes depleted of CD4 $4^{+} \mathrm{T}$ cells $(P=0.001)$.

To determine the effect of intranasal B24-C33 and the core $\mathrm{I}-\mathrm{A}^{\mathrm{g} 7}$-binding nonamer sequence, $\mathrm{B} 24-\mathrm{C} 32$, on spontaneous diabetes incidence, female NOD mice $(n=12$ per group) were given a single $40-\mu \mathrm{g}$ dose of each peptide, the parent B24-C36 peptide, or PBS carrier only at 8 weeks of age. B24-C36 had no effect on diabetes incidence: at 182 days of age $83 \%$ of mice had become diabetic compared with $92 \%$ of PBS controls. On the other hand, after treatment with B24-C33 or B24-C32, the incidence of diabetes (logrank survival analysis) was significantly reduced, being 33\% $(P=0.02)$ and $25 \%(P=0.01)$, respectively, at 154 days and $58 \%(P=0.03)$ and $25 \%(P=0.004)$, respectively, at 184 days (Figure 5).

\section{Discussion}

A sequence in proinsulin, spanning the cleavage site between the $\mathrm{B}$ chain of insulin and the C-peptide of proinsulin, is recognized by $\mathrm{T}$ cells from humans at risk for T1D (4) and NOD mice (5). Here we show in the NOD mouse that proinsulin B24-C36 comprises overlapping $\mathrm{CD}^{+}$and $\mathrm{CD}^{+} \mathrm{T}$ cell epitopes. $\mathrm{B} 25-\mathrm{C} 34$ is a novel MHC class I-restricted (K $\mathrm{K}^{\mathrm{d}}$-restricted) CTL epi- tope that overlaps the core MHC class II-binding (I-A ${ }^{\mathrm{g} 7}$-binding) nonamer, B24-C32, and limits the ability of the latter to prevent diabetes after intranasal administration. Although the B24-C36 peptide induced regulatory $\mathrm{CD} 4{ }^{+} \mathrm{T}$ cells after intranasal administration, it did not alter the incidence of spontaneous diabetes. The CTL epitope was disabled by truncation of B24-C36 at its C-terminus to eliminate the C34 valine, an anchor residue for binding into the $\mathrm{p} 9$ pocket of $\mathrm{K}^{\mathrm{d}}$. Without the $\mathrm{C} 34$ valine, the peptide cannot bind $\mathrm{K}^{\mathrm{d}}$, as demonstrated. However, it can still bind to $\mathrm{I}-\mathrm{Ag}^{\mathrm{g}}$ and, when administered intranasally, not only induced regulatory $\mathrm{T}$ cells but suppressed the development of diabetes. Interestingly, CTLs could be elicited not only by B25-C34 but also by the B24-C36 peptide, which also bound to $\mathrm{K}^{\mathrm{d}}$. Although MHC class I molecules are generally considered to accommodate shorter nonamer or decamer peptides, the C-terminal binding pocket of some MHC class I molecules can allow C-terminal peptide extensions out of the binding cleft (25). The only other CTL epitope reported in the NOD mouse, insulin $B$ chain 15-23 (26), also overlaps a $C D 4^{+} T$ cell epitope within the B chain 9-23 sequence. Contiguous or overlapping $\mathrm{CD}^{+}$and $\mathrm{CD}^{+} \mathrm{T}$ cell epitopes have been found as well in the two other islet autoantigens, tyrosine phosphatase-like insulinoma antigen-2 $(27,28)$ and glutamic acid decarboxylase (29). These findings suggest that a single combitope sequence may be processed by an APC and serve to efficiently elicit both helper $\mathrm{CD}^{+} \mathrm{T}$ cell and associated $\mathrm{CD} 8^{+} \mathrm{CTL}$ responses.

Although we detected B25-C34-specific CTLs in the NOD mouse spleen after subcutaneous priming, we were unable to detect their priming by intranasal B24-C36 administration. This may be due to the limited sensitivity of the ${ }^{51} \mathrm{Cr}$-release assay. We have used this assay to detect OVA-specific CTLs after low-dose intranasal OVA (30), but because OVA is a non-selfprotein, it would be recognized by a higher frequency

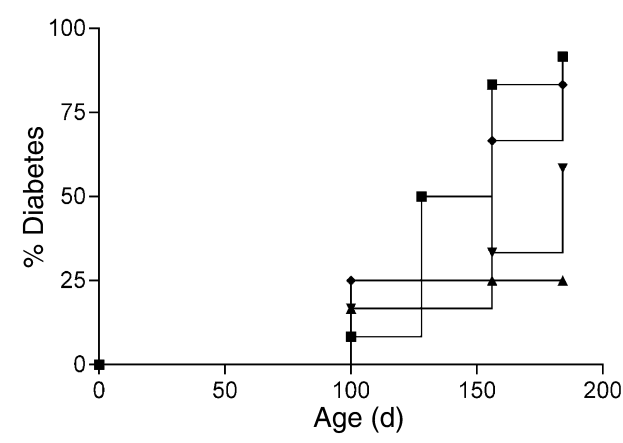

\section{Figure 5}

Disabling the B25-C34 CTL epitope permits diabetes prevention by proinsulin peptide. A single intranasal dose of mouse proinsulin B24-C36 (diamonds), B24-C33 (inverted triangles), or B24-C32 (triangles) peptide, or PBS carrier only (squares), was given to 8 -week-old female NOD mice ( $n=12$ per group). The experiment was terminated at 26 weeks of age, when the majority of control mice had become diabetic. 
of CTL precursors. Even so, when CTLs are primed by mucosal OVA, they exhibit lower lytic activity than when they are primed subcutaneously in adjuvant (20). It is also relevant that the CTLs generated by subcutaneous priming with B24-C36 in adjuvant exhibited lower lytic activity than CTLs primed to non-self-OVA or LLO peptides. Thus, a relatively low frequency of CTLs or a relatively low avidity of CTLs for B25-C34 self-peptide is likely to militate against the detection of these CTLs ex vivo after intranasal treatment.

Two findings implicate the B25-C34 CTL epitope in the pathogenesis of NOD mouse diabetes. First, disabling the CTL epitope by truncation of the C-terminal anchor residue at $\mathrm{C} 34$ uncovered the ability of the $\mathrm{N}$-terminal $\mathrm{CD}^{+}{ }^{+} \mathrm{T}$ cell epitope, $\mathrm{B} 24-\mathrm{C} 32 / 33$, to prevent diabetes after intranasal administration. Second, when B25-C34 was administered systemically to young mice, before the onset of insulitis, diabetes development was suppressed. Immunoprotection after systemic high-dose administration of a CTL epitope has previously been reported in a transgenic $T$ cell receptor (TCR) model of autoimmune diabetes (24). This effect of B25-C34 administration just before the appearance of insulitis is consistent with evidence that direct $\beta$ cell recognition by $\mathrm{MHC}$ class I-restricted $\mathrm{CD}^{+} \mathrm{T}$ cells is a requirement for the onset of insulitis (31).

Mucosal administration of autoantigen often confers only partial protection from experimental autoimmune disease and in some cases has been shown to exacerbate disease (32-34). In addition, trials in humans of oral myelin basic protein for multiple sclerosis (35), oral collagen type II for rheumatoid arthritis (36), and oral insulin for $\operatorname{T1D}(37,38)$ did not demonstrate clinical benefit. One explanation for these findings could be the simultaneous induction of protective immunity (mucosal tolerance), shown here to be mediated by regulatory $\mathrm{CD} 4^{+} \mathrm{T}$ cells, and pathogenic immunity mediated by CTL. Previously, in mice bearing OVAspecific TCRs and expressing OVA transgenically in pancreatic $\beta$ cells, a single oral dose of OVA was shown to activate CTLs, leading to autoimmune $\beta$ cell destruction and diabetes (20). Furthermore, pathogenic OVAspecific CTLs could be induced in mice by a variety of doses and schedules of oral, aerosol, or intranasal OVA that had been used by others to induce mucosal tolerance (30). These models reveal that mucosal administration of autoantigen may be a double-edged sword with the potential to induce not only protective but also pathogenic immunity. The outcome of mucosal antigen administration may therefore reflect a balance between protective and pathogenic immunity. In the context of autoimmune disease prevention, induction of CTL immunity could nullify the benefit of mucosal tolerance mediated by regulatory $\mathrm{T}$ cells and, in a worst-case scenario, exacerbate disease. Avoidance of CTL immunity should improve the efficacy and safety of mucosal autoantigen administration for preventing autoimmune disease. This may be achieved by mutating or deleting CTL epitopes, as shown here, or by blocking costimulation-dependent CTL activation as shown previously in a transgenic OVA model (39).

\section{Acknowledgments}

We thank Arno Mullbacher for the RMA-S-K ${ }^{d}$ cell line, Michelle Latimer for care of mice, Demetrios Kyrkas for technical assistance, Andrew Lew for comments on the manuscript, and Catherine O'Shea for secretarial assistance. This work was supported by the National Health and Medical Research Council of Australia, a Program Grant from the Juvenile Diabetes Research Foundation (to L.C. Harrison), and a grant from the Research Committee of the Technological Educational Institute of Epirus (to G.K. Papadopoulos).

1. Pugliese, A., et al. 1997. The insulin gene is transcribed in the human thymus and transcription levels correlate with allelic variation at the INS VNTR-IDDM2 susceptibility locus for type 1 diabetes. Nat. Genet. 15:293-297.

2. Vafiadis, P., et al. 2001. Class III alleles of the variable number of tandem repeat insulin polymorphism associated with silencing of thymic insulin predispose to type 1 diabetes. J. Clin. Endocrinol. Metab. 86:3705-3710.

3. French, M.B., et al. 1997. Transgenic expression of mouse proinsulin II prevents diabetes in nonobese diabetic mice [erratum 1997, 46:924]. Diabetes. 46:34-39.

4. Rudy, G., et al. 1995. Similar peptides from two beta cell autoantigens, proinsulin and glutamic acid decarboxylase, stimulate $\mathrm{T}$ cells of individuals at risk for insulin-dependent diabetes. Mol. Med. 1:625-633.

5. Chen, W., et al. 2001. Evidence that a peptide spanning the B-C junction of proinsulin is an early autoantigen epitope in the pathogenesis of type 1 diabetes. J. Immunol. 167:4926-4935.

6. Harrison, L.C., and Hafler, D.A. 2000. Antigen-specific therapy for autoimmune disease. Curr. Opin. Immunol. 12:704-711.

7. Faria, A.M., and Weiner, H.L. 1999. Oral tolerance: mechanisms and therapeutic applications. Adv. Immunol. 73:153-264.

8. Krause, I., Blank, M., and Shoenfeld, Y. 2000. Immunomodulation of experimental autoimmune diseases via oral tolerance. Crit. Rev. Immunol. 20:1-16.

9. Harrison, L.C., et al. 1997. A peptide-binding motif for I-A(g7), the class II major histocompatibility complex (MHC) molecule of NOD and Biozzi AB/H mice. J. Exp. Med. 185:1013-1021.

10. Rammensee, H.G., Bachmann, J., Emmerich, N., and Stevanovich, S. An Internet Database for MHC Ligands and Peptide Motifs. http://134.2.96.221/scripts/MHCserver.dll/home.htm.

11. Taylor, R., and Parker, K. An Internet Database for HLA Peptide Motifs. http://bimas.dcrt.nih.gov/.

12. Corper, A.L., et al. 2000. A structural framework for deciphering the link between I-Ag7 and autoimmune diabetes. Science. 288:505-511.

13. Latek, R.R., et al. 2000. Structural basis of peptide binding and presentation by the type I diabetes-associated MHC class II molecule of NOD mice. Immunity. 12:699-710.

14. Moustakas, A.K., Routsias, J., and Papadopoulos, G.K. 2000. Modeling of the MHC II allele I-A(g7) of NOD mouse: $\mathrm{pH}$-dependent changes in specificity at pockets 9 and 6 explain several of the unique properties of this molecule. Diabetologia. 43:609-624.

15. Fremont, D.H., Monnaie, D., Nelson, C.A., Hendrickson, W.A., and Unanue, E.R. 1998. Crystal structure of I-Ak in complex with a dominant epitope of lysozyme. Immunity. 8:305-317.

16. Madden, D.R., Garboczi, D.N., and Wiley, D.C. 1993. The antigenic identity of peptide-MHC complexes: a comparison of the conformations of five viral peptides presented by HLA-A2. Cell. 75:693-708.

17. Wong, F.S., Moustakas, A.K., Wen, L., Papadopoulos, G.K., and Janeway, C.A. 2002. Analysis of structure and function relationships of an autoantigenic peptide of insulin bound to H-2K(d) that stimulates CD8 $\mathrm{T}$ cells in insulin-dependent diabetes mellitus. Proc. Natl. Acad. Sci. U. S. A. 99:5551-5556.

18. Mullbacher, A., and Lobigs, M. 1995. Up-regulation of MHC class I by flavivirus-induced peptide translocation into the endoplasmic reticulum. Immunity. 3:207-214.

19. Sijts, A.J., and Palmer, E.G. 1997. Enhanced intracellular dissociation of major histocompatibility complex class I-associated peptides: a mechanism for optimizing the spectrum of cell surface-presented cytotoxic T lymphocyte epitopes. J. Exp. Med. 185:1403-1411.

20. Blanas, E., Carbone, F.R., Allison, J., Miller, J.F., and Heath, W.R. 1996 Induction of autoimmune diabetes by oral administration of autoantigen. Science. 274:1707-1709. 
21. Clayton, J.P., et al. 1989. Peptide-specific prevention of experimental allergic encephalomyelitis. Neonatal tolerance induced to the dominant $\mathrm{T}$ cell determinant of myelin basic protein. J. Exp. Med. 169:1681-1691.

22. Liblau, R., Tisch, R., Bercovici, N., and McDevitt, H.O. 1997. Systemic antigen in the treatment of T-cell-mediated autoimmune diseases. Immunol. Today. 18:599-604.

23. Heeger, P.S., et al. 2000. Revisiting tolerance induced by autoantigen in incomplete Freund's adjuvant. J. Immunol. 164:5771-5781.

24. Bercovici, N., et al. 2000. Systemic administration of agonist peptide blocks the progression of spontaneous CD8-mediated autoimmune diabetes in transgenic mice without bystander damage. J. Immunol. 165:202-210.

25. Horig, H., Young, A.C., Papadopoulos, N.J., DiLorenzo, T.P., and Nathenson, S.G. 1999. Binding of longer peptides to the $\mathrm{H}-2 \mathrm{~Kb}$ heterodimer is restricted to peptides extended at their $\mathrm{C}$ terminus: refinement of the inherent MHC class I peptide binding criteria. J. Immunol. 163:4434-4441

26. Wong, F.S., et al. 1999. Identification of an MHC class I-restricted autoantigen in type 1 diabetes by screening an organ-specific cDNA library. Nat. Med. 5:1026-1031.

27. Honeyman, M.C., Stone, N.L., and Harrison, L.C. 1998. T-cell epitopes in type 1 diabetes autoantigen tyrosine phosphatase IA- 2: potential for mimicry with rotavirus and other environmental agents. Mol. Med. 4:231-239.

28. Takahashi, K., Honeyman, M.C., and Harrison, L.C. 2001. Cytotoxic T cells to an epitope in the islet autoantigen IA-2 are not disease-specific. Clin. Immunol. 99:360-364.

29. Quinn, A., McInerney, M.F., and Sercarz, E.E. 2001. MHC class I-restricted determinants on the glutamic acid decarboxylase 65 molecule induce spontaneous CTL activity. J. Immunol. 167:1748-1757.

30. Hanninen, A., Braakhuis, A., Heath, W.R., and Harrison, L.C. 2001 Mucosal antigen primes diabetogenic cytotoxic T-lymphocytes regard- less of dose or delivery route. Diabetes. 50:771-775.

31. Kay, T.W.H., Parker, J.L., Stephens, L.A., Thomas, H.E., and Allison, J. 1996. RIP-beta 2-microglobulin transgene expression restores insulitis, but not diabetes, in beta 2 -microglobulin null nonobese diabetic mice. J. Immunol. 57:3688-3693.

32. Miller, A., Lider, O., Abramsky, O., and Weiner, H.L. 1994. Orally administered myelin basic protein in neonates primes for immune responses and enhances experimental autoimmune encephalomyelitis in adult animals. Eur. J. Immunol. 24:1026-1032.

33. Terato, K., Ye, X.J., Miyahara, H., Cremer, M.A., and Griffiths, M.M. 1996. Induction by chronic autoimmune arthritis in $\mathrm{DBA} / 1$ mice by oral administration of type II collagen and Escherichia coli lipopolysaccharide. Br. J. Rheumatol. 35:828-838.

34. Bellmann, K., Kolb, H., Rastegar, S., Jee, P., and Scott, F.W. 1998. Potential risk of oral insulin with adjuvant for the prevention of Type I diabetes: a protocol effective in NOD mice may exacerbate disease in BB rats. Diabetologia. 41:844-847.

35. Weiner, H.L., et al. 1993. Double-blind pilot trial of oral tolerization with myelin antigens in multiple sclerosis. Science. 259:1321-1324.

36. McKown, K.M., et al. 1999. Lack of efficacy of oral bovine type II collagen added to existing therapy in rheumatoid arthritis. Arthritis Rheum. 42:1204-1208.

37. Pozzilli, P., et al. 2000. No effect of oral insulin on residual beta-cell function in recent-onset type I diabetes (the IMDIAB VII). IMDIAB Group. Diabetologia. 43:1000-10004.

38. Chaillous, L., et al. 2000. Oral insulin administration and residual betacell function in recent-onset type 1 diabetes: a multicentre randomised controlled trial. Diabete Insuline Orale group. Lancet. 356:545-549.

39. Hanninen, A., Martinez, N.R., Davey, G.M., Heath, W.R., and Harrison, L.C. 2002. Transient blockade of CD40 ligand dissociates pathogenic from protective mucosal immunity. J. Clin. Invest. 109:261-267. doi:10.1172/JCI200213720. 